\title{
Crossmodal temporal discrimination: Assessing the predictions of a general pacemaker-counter model
}

\author{
ROLF ULRICH and JUDITH NITSCHKE \\ University of Tübingen, Tübingen, Germany \\ and \\ THOMAS RAMMSAYER \\ University of Göttingen, Göttingen, Germany
}

\begin{abstract}
In this study, an extended pacemaker-counter model was applied to crossmodal temporal discrimination. In three experiments, subjects discriminated between the durations of a constant standard stimulus and a variable comparison stimulus. In congruent trials, both stimuli were presented in the same sensory modality (i.e., both visual or both auditory), whereas in incongruent trials, each stimulus was presented in a different modality. The model accounts for the finding that temporal discrimination depends on the presentation order of the sensory modalities. Nevertheless, the model fails to explain why temporal discrimination was much better with congruent than with incongruent trials. The discussion considers possibilities to accommodate the model to this and other shortcomings.
\end{abstract}

Time is an essential component of our mental life. Hence, it is not surprising that for many years, philosophers and psychologists have been intrigued by the question of how time enters into our experiences and thus shapes our cognitions (Roeckelein, 2000). For example, the great philosopher Immanuel Kant (1787/1998) argued that space and time are basic intuitions ("a priori Anschauungen") that structure our cognition. In addition, he believed that time involves a more subjective intuition than does space (see Boring, 1957). Thus, among other things, the study of time perception derives from Kant's proposal about time. The perception of time also attracted early psychophysicists (e.g., Mach, 1865; Vierordt, 1868) and has remained an active field of research in psychology up to the present day (see Grondin, 2001; Meck, 2003). More recently, time perception has become a major object of research in the field of the cognitive neurosciences (see Lewis \& Miall, 2003; Nobre \& O’Reilly, 2004).

The question of how humans perceive time, however, is still a matter of controversy (see Grondin, 2001). Nowadays, various theories exist about the mechanism(s) underlying time perception. Many share the core assump-

This work was supported by the Deutsche Forschungsgemeinschaft (U1 116/6-3, RA 450/9-3). We thank Susana Ruiz Fernández and Anette Mannhart for their assistance in data collection, and Simon Grondin, Bruno Repp, Bettina Rolke, and an anonymous reviewer for constructive and helpful comments. Correspondence concerning this article should be addressed to R. Ulrich, Department of Cognitive and Biological Psychology, Psychological Institute, University of Tübingen, Friedrichstr. 21, 72072 Tübingen, Germany (e-mail: ulrich@uni-tuebingen.de). tion of an internal clock based on neuronal counting (e.g., Allan \& Kristofferson, 1974; Creelman, 1962; Gibbon, 1991; Grondin, 2003; Treisman, Faulkner, Naish, \& Brogan, 1990). The main features of such an internal-clock mechanism are a pacemaker and an accumulator. The pacemaker generates pulses, and these are registered by the accumulator. The number of pulses counted by the accumulator during a certain physical time interval represents the perceived duration of this interval. This pacemaker-counter model (PCM) has been successfully applied to time-related behavior of humans (Bendixen, Grimm, \& Schröger, 2005; Killeen \& Taylor, 2000; Penney, Gibbon, \& Meck, 2000; Rammsayer \& Ulrich, 2001) and animals (Fetterman \& Killeen, 1995; Gibbon, 1977).

The present study tests new predictions of PCM. More specifically, we generalized the model such that it can be applied to a crossmodal temporal discrimination task. In this task, subjects were asked to discriminate between the duration of a constant standard and the duration of a variable comparison stimulus. The sensory modalities of the standard and the comparison were either congruent or incongruent. In congruent trials, both the comparison and the standard stimulus were either auditory or visual - that is, auditory-auditory (a-a) or visual-visual $(\mathrm{v}-\mathrm{v})$ - whereas in incongruent trials, one stimulus was auditory and the other visual - that is, auditory-visual $(\mathrm{a}-\mathrm{v})$ or visual-auditory ( $v-a)$. As shown below, PCM makes intriguing predictions for this task. These predictions were assessed through the results of three experiments. In Experiments 1 and 2, the standard preceded the comparison, whereas in Experiment 3, the comparison preceded the standard. 


\section{Applying PCM to Crossmodal Temporal Discrimination}

In this section, we extend a general version of the PCM for temporal discrimination (Rammsayer \& Ulrich, 2001) to the more complicated situation in which the standard stimulus and the comparison stimulus differ in sensory modality. The traditional formulation of PCM (Creelman, 1962) assumes that the pulse rate is identical for both the standard and comparison intervals. Strong evidence exists, however, that the internal clock runs at a faster rate when the stimulus is auditory than when it is visual (Penney et al., 2000; Wearden, Edwards, Fakhri, \& Percival, 1998). Thus, this traditional formulation of PCM cannot be applied to a bimodal temporal discrimination task, in which the standard and comparison stimuli differ in sensory modality. To adapt the model to a bimodal situation, we will assume that the mean interpulse time for auditory stimuli is shorter than the one for visual stimuli. On the basis of this assumption, we will derive the predicted psychometric function of PCM for congruent and incongruent trials, as well as the difference limen $(D L)$ and the constant error $(C E)$ of this function.

Creelman's (1962) original PCM assumes that the pulse stream follows a Poisson process. This process implies an exponential interpulse distribution with a modal value of zero; however, this assumption is generally implausible (see Rammsayer \& Ulrich, 2001). For example, such a property is incompatible with the refractory period of neurons, since some time needs to elapse after the production of a pulse before the next pulse can be generated. Hence, the interpulse time could never attain a value of zero. Therefore, Rammsayer and Ulrich (2001) generalized the assumptions of PCM and provided quantitative predictions that do not require specific distributional assumptions about the interpulse time.

In order to derive the psychometric function of the generalized PCM, let $t_{\mathrm{s}}$ and $t_{\mathrm{c}}$ be the durations of the standard interval and the comparison interval, respectively. In any trial, $t_{\mathrm{c}}$ may be shorter than, longer than, or equal to $t_{\mathrm{s}}$. Furthermore, let $N\left(t_{\mathrm{s}}\right)$ be the number of pulses counted during $t_{\mathrm{s}}$, and likewise let $N\left(t_{\mathrm{c}}\right)$ be the number of pulses counted during $t_{\mathrm{c}}$. As in the traditional PCM, subjects are assumed to judge the comparison to be longer than the standard if $N\left(t_{\mathrm{c}}\right)>N\left(t_{\mathrm{s}}\right)$. Therefore, the response probability of this judgment " $\mathrm{C}>\mathrm{S}$ " is computed as

$$
\begin{aligned}
\operatorname{Pr}\left\{“ \mathrm{C}>\mathrm{S} " \mid t_{\mathrm{s}}, t_{\mathrm{c}}\right\} & =\operatorname{Pr}\left\{N\left(t_{\mathrm{c}}\right)>N\left(t_{\mathrm{s}}\right)\right\} \\
& =\operatorname{Pr}\left\{N\left(t_{\mathrm{c}}\right)-N\left(t_{\mathrm{s}}\right)>0\right\} \\
& =\operatorname{Pr}\left\{N\left(t_{\mathrm{s}}\right)-N\left(t_{\mathrm{c}}\right) \leq 0\right\} \\
& =\operatorname{Pr}\left\{D\left(t_{\mathrm{s}}, t_{\mathrm{c}}\right) \leq 0\right\} .
\end{aligned}
$$

In other words, the response probability $\operatorname{Pr}\left\{\right.$ “ $\mathrm{C}>\mathrm{S}$ ” $\left.\mid t_{\mathrm{s}}, t_{\mathrm{c}}\right\}$ corresponds to the probability of the event that the difference $D\left(t_{\mathrm{s}}, t_{\mathrm{c}}\right)=N\left(t_{\mathrm{s}}\right)-N\left(t_{\mathrm{c}}\right)$ is less than or equal to zero.

According to a theorem of renewal theory (see Rammsayer \& Ulrich, 2001, p. 276), the number of pulses $N(t)$ counted during the time interval $t$ is approximately normally distributed, with mean $\mathrm{E}[N(t)]=t / \mu$ and variance
$\operatorname{Var}[N(t)]=t \cdot \sigma^{2} / \mu^{3}$. The constants $\mu$ and $\sigma$ denote the mean and the standard deviation of the interpulse duration. ${ }^{1}$ Note that this theorem holds for any interpulse distribution, and therefore, no specific assumptions about this distribution will be required for deriving predictions from this model.

\section{Predicted Psychometric Function}

This theorem from renewal theory allows the computation of the response probability $\operatorname{Pr}\left\{“ \mathrm{C}>\mathrm{S}\right.$ " $\left.\mid t_{\mathrm{s}}, t_{\mathrm{c}}\right\}$, and consequently of the predicted psychometric function. Because $N\left(t_{\mathrm{s}}\right)$ and $N\left(t_{\mathrm{c}}\right)$ are (approximately) normally distributed, the difference $D\left(t_{\mathrm{s}}, t_{\mathrm{c}}\right)$ must also be normally distributed. Specifically, the mean and the variance associated with this difference are

$$
\begin{aligned}
\mathrm{E}\left[D\left(t_{\mathrm{s}}, t_{\mathrm{c}}\right)\right] & =\mathrm{E}\left[N\left(t_{\mathrm{s}}\right)\right]-\mathrm{E}\left[N\left(t_{\mathrm{c}}\right)\right] \\
& =\frac{t_{\mathrm{s}}}{\mu_{\mathrm{s}}}-\frac{t_{\mathrm{c}}}{\mu_{\mathrm{c}}}
\end{aligned}
$$

and

$$
\begin{aligned}
\operatorname{Var}\left[D\left(t_{\mathrm{s}}, t_{\mathrm{c}}\right)\right] & =\operatorname{Var}\left[N\left(t_{\mathrm{s}}\right)\right]+\operatorname{Var}\left[N\left(t_{\mathrm{c}}\right)\right] \\
& =\frac{t_{\mathrm{s}} \cdot \sigma_{\mathrm{s}}^{2}}{\mu_{\mathrm{s}}^{3}}+\frac{t_{\mathrm{c}} \cdot \sigma_{\mathrm{c}}^{2}}{\mu_{\mathrm{c}}^{3}} .
\end{aligned}
$$

The constants $\mu_{\mathrm{s}}$ and $\sigma_{\mathrm{s}}$ are the mean and the standard deviation of the interpulse distribution of the counting process that prevails during the standard interval. The corresponding mean and standard deviation of the counting process during the comparison interval are $\mu_{\mathrm{c}}$ and $\sigma_{\mathrm{c}}$, respectively. Hence, if the standard is auditory and the comparison is visual, one would assume $\mu_{\mathrm{s}}<\mu_{\mathrm{c}}$, whereas $\mu_{\mathrm{s}}>\mu_{\mathrm{c}}$ should be assumed if the standard is visual and the comparison auditory.

Since $D\left(t_{\mathrm{s}}, t_{\mathrm{c}}\right)$ is approximately normally distributed with a mean and variance given by Equations 2 and 3, respectively, Equation 1 extends to

$$
\begin{aligned}
\operatorname{Pr}\left\{\text { “C }>\mathrm{S} " \mid t_{\mathrm{s}}, t_{\mathrm{c}}\right\} & =\Phi\left[\frac{0-\mathrm{E}\left[D\left(t_{\mathrm{s}}, t_{\mathrm{c}}\right)\right]}{\sqrt{\operatorname{Var}\left[D\left(t_{\mathrm{s}}, t_{\mathrm{c}}\right)\right]}}\right] \\
& =\Phi\left[\frac{0-\left(\frac{t_{\mathrm{s}}}{\mu_{\mathrm{s}}}-\frac{t_{\mathrm{c}}}{\mu_{\mathrm{c}}}\right)}{\sqrt{\frac{t_{\mathrm{s}} \cdot \sigma_{\mathrm{s}}^{2}}{\mu_{\mathrm{s}}^{3}}+\frac{t_{\mathrm{c}} \cdot \sigma_{\mathrm{c}}^{2}}{\mu_{\mathrm{c}}^{3}}}}\right] \\
& =\Phi\left[\frac{\frac{t_{\mathrm{c}}}{\mu_{\mathrm{c}}}-\frac{t_{\mathrm{s}}}{\mu_{\mathrm{s}}}}{\sqrt{\frac{t_{\mathrm{s}} \cdot \sigma_{\mathrm{s}}^{2}}{\mu_{\mathrm{s}}^{3}}+\frac{t_{\mathrm{c}} \cdot \sigma_{\mathrm{c}}^{2}}{\mu_{\mathrm{c}}^{3}}}}\right] .
\end{aligned}
$$

Note that the symbol $\Phi$ represents the cumulative distribution function of a standard normal distribution. (It should be noted, however, that the predicted shape of the psychometric function does not correspond to the shape of a nor- 
mal distribution. This is because the variable $t_{\mathrm{c}}$ not only occurs in the numerator but also in the denominator.)

The last expression can be employed to establish the psychometric function for the temporal discrimination task. This is achieved by plotting the response probability $\operatorname{Pr}\left\{\right.$ “ $\mathrm{C}>\mathrm{S}$ " $\left.\mid t_{\mathrm{s}}, t_{\mathrm{c}}\right\}$ against the duration $t_{\mathrm{c}}$ of the comparison interval. Examples of the predicted psychometric functions are depicted in Figure 1. This example displays psychometric functions for a standard duration of $t_{\mathrm{s}}=100 \mathrm{msec}$ and for each modality combination of standard and comparison $(\mathrm{a}-\mathrm{a}, \mathrm{v}-\mathrm{v}, \mathrm{a}-\mathrm{v}$, and $\mathrm{v}-\mathrm{a})$. In agreement with previous studies, a smaller mean interpulse time for auditory intervals than for visual intervals is assumed. In addition, we assume a larger standard deviation for the visual than for the auditory stimuli, since previous results have indicated a larger pacemaker variability for visual than for auditory intervals (see, e.g., Wearden et al., 1998).

Figure 1 reveals several specific features. First, as one would expect, response probability $\operatorname{Pr}\left\{\right.$ “C $>\mathrm{S}$ " $\left.\mid t_{\mathrm{s}}, t_{\mathrm{c}}\right\}$ increases monotonically with the duration $t_{\mathrm{c}}$ of the comparison. Second, the predicted point of subjective equality (PSE) of the psychometric functions is equal to the standard duration $(100 \mathrm{msec})$ in congruent but not in incongruent trials. Third, the psychometric function for the congruent auditory condition (a-a) is steeper (i.e., has a smaller $D L$ ) than the one for the congruent visual condition $(\mathrm{v}-\mathrm{v})$. Fourth, the magnitude of PSE in incongruent trials depends on whether the comparison is visual or auditory. If it is auditory, the duration of the comparison has to be shorter than that of the visual standard in order for both intervals to be perceived as equally long. If the com- parison is visual, however, the duration of the visual comparison has to be longer than that of the auditory standard for subjective equality to be achieved. Both predictions simply reflect the assumption that the internal clock runs faster for auditory than for visual signals.

Finally, the presumably most striking and counterintuitive prediction is that the slope of the psychometric function in $\mathrm{v}-\mathrm{a}$ trials is steeper than in $\mathrm{a}-\mathrm{v}$ trials. In other words, PCM predicts a smaller $D L$ in the former than in the latter condition. This nonobvious order effect on $D L$ is basically due to the longer interpulse time for visual than for auditory intervals. For example, consider an auditory standard of $100 \mathrm{msec}$ and assume that one pulse is counted, on average, every $5 \mathrm{msec}$ during this auditory interval. Consequently, 20 pulses on average will be counted during the interval. Now conceive a visual comparison with a mean interpulse time of $10 \mathrm{msec}$ and assume that an average of 25 pulses must be registered during the visual interval in order for the comparison to be perceived as longer than the standard on $75 \%$ of all trials. In this case, the PSE would correspond to $20 \cdot 10=200 \mathrm{msec}$, and the $D L$ would reflect the additional duration for generating the five remaining pulses - that is, $D L=5 \cdot 10=$ $50 \mathrm{msec}$. For the reversed stimulus order, only 10 pulses would be counted on average during the standard interval. Thus, the PSE would equal $10 \cdot 5=50 \mathrm{msec}$. Crucially, however, the comparison has to be further lengthened by $D L=5 \cdot 5=25 \mathrm{msec}$ in order to generate 5 more pulses, on average, to attain a discrimination probability of .75 , and this lengthening is less than that required for the comparison in the original order. In summary, then, the pre-

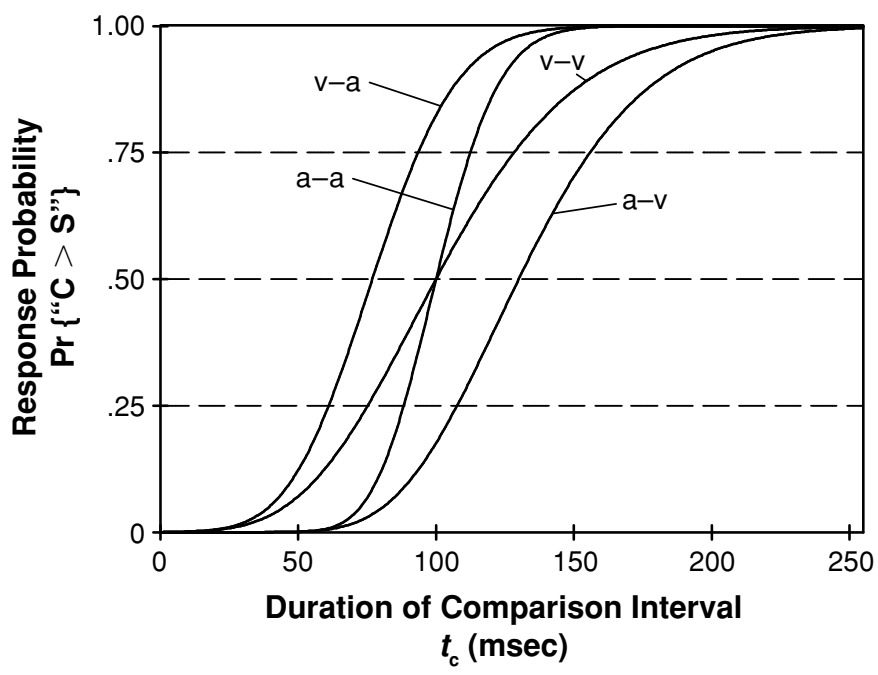

Figure 1.Predicted psychometric functions of the pacemaker-counter model. Each graph depicts the response probability $\operatorname{Pr}\left\{“ \mathrm{C}>\mathrm{S}\right.$ " $\left.\mid t_{\mathrm{s}}, t_{\mathrm{c}}\right\}$ as a function of the duration $t_{\mathrm{c}}$ of the comparison interval. The duration of the standard, $t_{\mathrm{s}}$, is equal to 100 msec. $v-a$, visual standard with auditory comparison; a-a, auditory standard with auditory comparison; $v-v$, visual standard with visual comparison; a-v, auditory standard with visual comparison. The mean and the standard deviation $(\mu, \sigma)$ of the interpulse time are $(\mu=10 \mathrm{msec}, \sigma=4 \mathrm{msec})$ for auditory intervals but ( $\mu=13 \mathrm{msec}, \sigma=10 \mathrm{msec}$ ) for visual ones. 
dicted order effect on $D L$ can also be attributed to different clock speeds for visual and auditory stimuli. ${ }^{2}$

\section{Predicted $D L$ and $C E$ as Functions of Congruency, Modality of the Standard, and Standard Duration}

In order to enhance the comparison of the predicted with the obtained results of this article, it is useful to derive $D L$ and $C E$ of the generalized PCM. First, $C E$ is commonly defined as the difference between the value of $t_{\mathrm{c}}(.5)$, which yields $\operatorname{Pr}\left\{“ \mathrm{C}>\mathrm{S}\right.$ ” $\left.\mid t_{\mathrm{s}}, t_{\mathrm{c}}\right\}=.5$ (i.e., $P S E$ ), and the standard duration $t_{\mathrm{s}}$ (i.e., the point of objective equality). The $C E$ can be negative, zero, or positive. A positive $C E$ means that subjects tend to overestimate the duration of the standard. By contrast, a negative $C E$ indicates an underestimation of the standard. ${ }^{3}$ According to Equation 4, and because $\Phi(0)=.5$, the value of $t_{\mathrm{c}}(.5)$ must satisfy the equation

$$
\frac{t_{\mathrm{c}}(.5)}{\mu_{\mathrm{c}}}-\frac{t_{\mathrm{s}}}{\mu_{\mathrm{s}}}=0 \text {. }
$$

Solving this equation for $t_{\mathrm{c}}(.5)$ yields the $P S E$, and inserting the resulting expression into the definition $C E=$ $P S E-t_{\mathrm{s}}$ gives

$$
C E=t_{\mathrm{s}} \cdot\left(\frac{\mu_{\mathrm{c}}}{\mu_{\mathrm{s}}}-1\right) .
$$

Note that the predicted $C E$ is zero if $\mu_{\mathrm{s}}=\mu_{\mathrm{c}}$, negative if $\mu_{\mathrm{s}}>\mu_{\mathrm{c}}$, and positive if $\mu_{\mathrm{s}}<\mu_{\mathrm{c}}$.

Second, $D L$ is commonly defined as half the interquartile range of the corresponding psychometric functionthat is,

$$
D L=\frac{t_{\mathrm{c}}(.75)-t_{\mathrm{c}}(.25)}{2},
$$

where $t_{\mathrm{c}}(.25)$ and $t_{\mathrm{c}}(.75)$ are those values of $t_{\mathrm{c}}$ that yield $\operatorname{Pr}\left\{“ \mathrm{C}>\mathrm{S}\right.$ " $\left.\mid t_{\mathrm{s}}, t_{\mathrm{c}}\right\}=.25$ and $\operatorname{Pr}\left\{“ \mathrm{C}>\mathrm{S}\right.$ " $\left.\mid t_{\mathrm{s}}, t_{\mathrm{c}}\right\}=.75$, respectively. Proceeding from this definition and from Equation 4, it can be shown that the predicted $D L$ for PCM is as shown in Equation 8 at the bottom of the page, with $z=0.6744$.

The upper panel of Figure 2 provides a numerical illustration of the predicted effects in a bimodal temporal discrimination task. Specifically, it shows the predicted $D L$ and $C E$ as functions of congruency, sensory modality of the standard, and standard duration $t_{\mathrm{s}}$. First, as one would expect, $D L$ is larger for the longer standard. Second, $D L$ is predicted to be somewhat larger for visual than for auditory standards. Third, $D L$ tends to be slightly smaller in congruent than in incongruent trials. Finally, the factors congruency and sensory modality are predicted to interact strongly. As was explained earlier, $D L$ is predicted to be

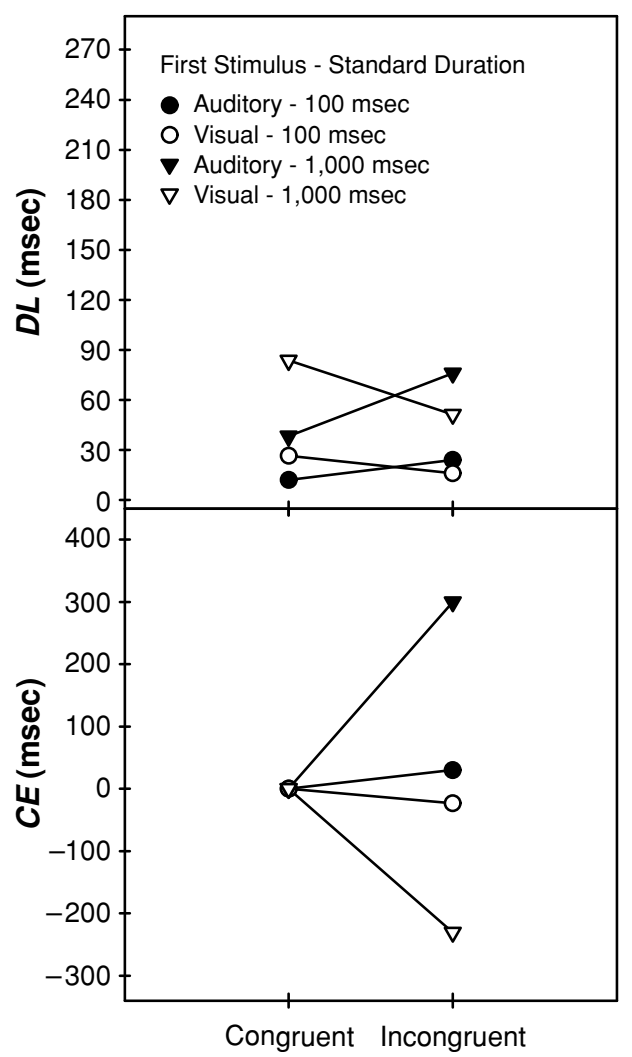

Figure 2. Predicted difference limen (DL, upper panel) and constant error ( $C E$, lower panel) of the PCM as a function of congruency, modality of the standard, and standard duration. The legend in the upper panel indicates the modality of the first stimulus and the duration of the standard; for example, "Auditory 100 msec" means that the first stimulus is auditory and the standard duration is $\mathbf{1 0 0}$ msec. The mean and the standard deviation $(\mu, \sigma)$ of the interpulse time are $(\mu=10 \mathrm{msec}, \sigma=4 \mathrm{msec})$ for auditory intervals but ( $\mu=13 \mathrm{msec}, \sigma=10 \mathrm{msec})$ for visual ones.

larger in $\mathrm{a}-\mathrm{v}$ than in $\mathrm{v}-\mathrm{a}$ trials and, as one would expect, larger in $\mathrm{v}-\mathrm{v}$ than in $\mathrm{a}-\mathrm{a}$ trials. In addition, the counterintuitive interaction becomes amplified as standard duration increases. The lower panel of Figure 2 reveals the predicted $C E$. In agreement with the previous analysis, and as one would expect, the $C E$ is zero in congruent trials and nonzero in incongruent trials. Specifically, a negative $C E$ is predicted for $\mathrm{v}-\mathrm{a}$ trials and a positive $C E$ for $\mathrm{a}-\mathrm{v}$ trials. According to PCM, the absolute size of $C E$ in these incongruent trials should increase with standard duration.

We report the results of three experiments to assess the predictions of PCM for crossmodal discrimination. Specifically, we investigated whether the psychophysical data reveal a pattern qualitatively similar to the one in Figure 2.

$$
D L=\frac{z \cdot \sqrt{z^{2} \cdot \sigma_{\mathrm{c}}^{4} \cdot \sigma_{\mathrm{s}}^{2}+4 \cdot t_{\mathrm{s}} \cdot \mu_{\mathrm{c}}^{2} \cdot\left(\mu_{\mathrm{c}}^{2} \cdot \sigma_{\mathrm{s}}^{2} / \mu_{\mathrm{s}}+\mu_{\mathrm{s}} \cdot \sigma_{\mathrm{c}}^{2}\right)}}{2 \cdot \mu_{\mathrm{c}} \cdot \mu_{\mathrm{s}}}
$$




\section{EXPERIMENT 1}

Experiment 1 employed a temporal discrimination task. On each trial, two successive time intervals were presented. The first interval was the constant standard, and the second was the variable comparison. Subjects had to indicate whether the comparison appeared to be shorter or longer than the standard. In congruent trials, the sensory modalities of both the standard and the comparison were identical $(\mathrm{a}-\mathrm{a}$ or $\mathrm{v}-\mathrm{v})$, whereas in incongruent trials the modalities of the stimuli differed $(\mathrm{a}-\mathrm{v}$ or $\mathrm{v}-\mathrm{a})$. The duration of the standard was either short $(100 \mathrm{msec})$ or long $(1,000 \mathrm{msec})$.

When subjects are asked to estimate or compare time intervals in the range of seconds, subvocal counting becomes a very common timing strategy (Grondin, Meilleur-Wells, \& Lachance, 1999; Poynter, 1989). However, counting has been shown to be an ineffective strategy for the timing of intervals below approximately 1,200 msec (Grondin et al., 1999). Therefore, in order to avoid explicit counting as an auxiliary timing strategy, the standard interval for temporal discrimination of longer intervals was chosen not to exceed the critical duration of $1,200 \mathrm{msec}$.

\section{Method}

Subjects. The subjects were 3 male and 17 female adult volunteers ranging from 19 to 40 years in age $(M=25.4, S D=5.0)$. All subjects were undergraduate or graduate students at the University of Tübingen and were paid $€ 7.50$ for taking part in this experiment. All had normal hearing and normal or corrected-to-normal vision. They were naive about the purpose of the experiment.

Apparatus and Stimuli. A PC controlled the presentation of the standard and comparison stimuli as well as the recording of the subjects' responses. The standard and comparison stimuli were filled auditory or visual intervals. The auditory stimulus was a white-noise burst (55.7 dB SPL) generated by a SoundBlaster-compatible sound card and presented through headphones (Sony MDR-CD 550). The visual stimulus was generated by a green LED display (diameter $0.48^{\circ}$, viewing distance $60 \mathrm{~cm}$, luminance $48 \mathrm{~cd} / \mathrm{m}^{2}$ ), which was attached $1 \mathrm{~cm}$ above the center of the computer screen. The intensity of the LED was clearly above threshold, but not dazzling.

Procedure. Each subject was seated at a table with a keyboard and a computer monitor. A trial started with the presentation of a fixation point in the center of the monitor screen. Then, the subject initiated the trial sequence by pressing a designated start key on the computer keyboard. This keypress also terminated the presentation of the fixation point. After $1,000 \mathrm{msec}$, the standard was presented. Its duration was either 100 or $1,000 \mathrm{msec}$ and was kept constant within a block of trials. The modality of the standard was either visual or auditory and varied randomly from trial to trial. Presentation of the variable comparison started $1,000 \mathrm{msec}$ after the offset of the standard. Again, the comparison was either a visual or an auditory stimulus. The subjects were required to indicate whether the comparison appeared to be shorter or longer than the standard by pressing one of two designated keys on the computer keyboard. This response also reactivated the fixation point. The next trial could be initiated by pressing the start key again.

There were eight different types of trials defined by the factorial combination of standard duration ( $100 \mathrm{vs} .1,000 \mathrm{msec})$, sensory modality of the standard (auditory vs. visual), and sensory modality of the comparison (auditory vs. visual). Each trial type was presented 48 times during a single experimental session of 384 trials. This sequence of 384 trials was divided into eight blocks of 48 trials each. Half of all subjects received at first four blocks with the short standard and then four blocks with the long standard. For the other half of the subjects, this order was reversed. For each subject, the order of congruent and incongruent trials was randomized within a single block. There was a rest period between blocks, during which performance feedback on the preceding blocks was provided on the monitor screen. The subjects initiated the next block when they felt ready to proceed.

Before the experiment, the subjects were informed that they would be presented with two successive stimuli and that the durations of the two stimuli would be slightly different. The subjects were told that the sensory modality of the two stimuli might be identical or different. They were instructed to ignore the variation of sensory modality and to focus on stimulus duration. Furthermore, the instructions emphasized accuracy, and there was no requirement to respond quickly.

To introduce the task, the experiment began with the presentation of 32 demonstration trials. After these trials, the subjects were asked whether they understood the procedure. The purpose of these demonstration trials was to familiarize the subjects with the stimuli. Then 96 practice trials were administered. These practice trials consisted of a random sample of 48 trials from the 100-msec condition and 48 trials from the 1,000-msec condition. The main session with the 384 experimental trials began after this training phase.

During the main session, the duration of the comparison interval was varied according to an adaptive rule (Kaernbach, 1991) to estimate the values $t_{\mathrm{c}}(.25)$ and $t_{\mathrm{c}}(.75)$ - that is, the two comparison intervals at which the response "comparison longer" was given with a probability of .25 and .75 , respectively. To estimate $t_{\mathrm{c}}(.25)$, the duration of the comparison interval was increased by $\Delta_{+} \mathrm{msec}$ if the subject had judged the comparison interval to be shorter, and decreased by $\Delta_{-}$msec after a "comparison longer" judgment. The opposite step sizes were employed for $t_{\mathrm{c}}(.75)$. This adaptive procedure was performed for each of the eight different trial types, resulting in 16 randomly interleaved runs. Because duration discrimination is easier for auditory than for visual intervals (see Goodfellow, 1934; Grondin, 2001) and because absolute precision of timing depends on the standard duration (Rammsayer \& Grondin, 2000), the step sizes $\Delta_{+}$and $\Delta_{-}$were adjusted for each trial type (Table 1 ). The starting value of the comparison for the $t_{\mathrm{c}}(.25)$ runs was equal to $t_{\mathrm{s}}-2 \Delta_{-}$. Analogously, the starting value for the $t_{\mathrm{c}}(.75)$ run was $t_{\mathrm{s}}+2 \Delta_{+}$. A maximum-likelihood procedure was used to estimate the difference limen $D L$ and the constant error $C E$ (see Mattes \& Ulrich, 1998).

\section{Results and Discussion}

Figure 3 depicts the average $D L$ and $C E$ as a function of standard duration, congruency, and sensory modality of the first stimulus. It is obvious that the results resemble the qualitative predictions of PCM. A separate three-way ANOVA for these three within-subjects factors was performed on $D L$ and $C E$ to provide a more explicit assessment of the data.

Table 1

Step Sizes $\Delta_{+}$and $\Delta_{-}$(in Milliseconds) to Estimate the Comparison Interval $\boldsymbol{t}_{\mathrm{c}}(\mathbf{7 5})$ for Each Standard Duration and Each Stimulus Combination

\begin{tabular}{|c|c|c|c|c|}
\hline Standard (msec) & $\mathrm{v}-\mathrm{v}$ & $\mathrm{a}-\mathrm{a}$ & $\mathrm{v}-\mathrm{a}$ & $\mathrm{a}-\mathrm{v}$ \\
\hline \multicolumn{5}{|l|}{$\Delta_{+}$} \\
\hline 100 & 8 & 3 & 10 & 10 \\
\hline \multicolumn{5}{|l|}{1,000} \\
\hline 100 & 24 & 9 & 30 & 30 \\
\hline 1,000 & 240 & 90 & 300 & 300 \\
\hline
\end{tabular}

Note-For the $t_{\mathrm{c}}(.25)$ runs, the values of $\Delta_{+}$and $\Delta_{-}$above were interchanged. 


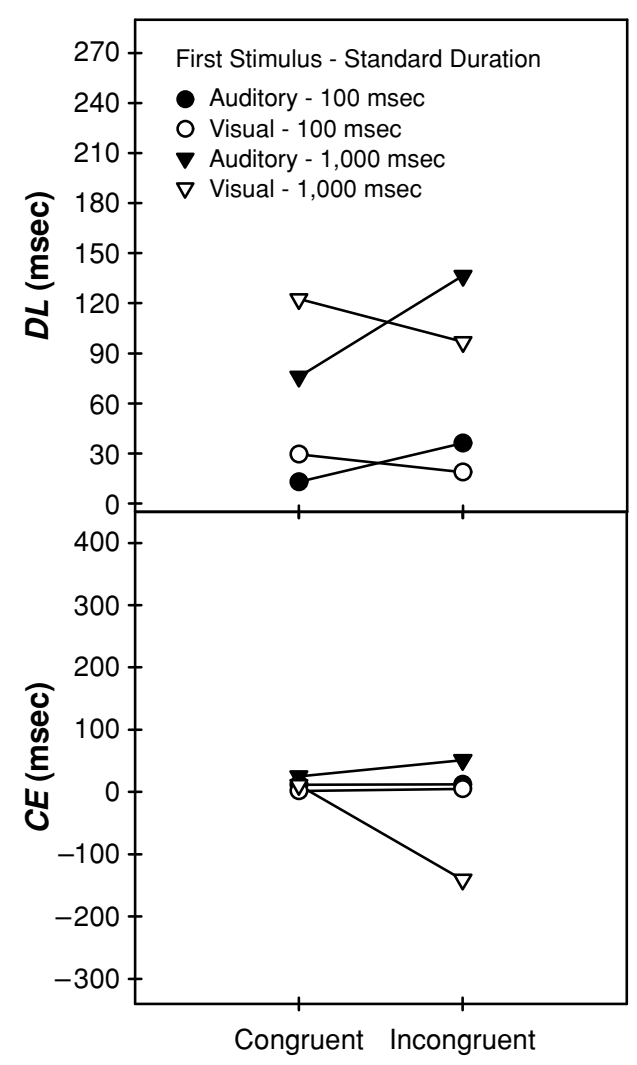

Figure 3. Results of Experiment 1: Mean difference limen ( $D L$, upper panel) and constant error ( $C E$, lower panel) as a function of congruency, modality of the standard, and standard duration. The legend in the upper panel indicates the modality of the first stimulus and the duration of the standard; for example, "Auditory - 100 msec" means that the first stimulus is auditory and the standard duration is $\mathbf{1 0 0}$ msec. Following the suggestion made by Loftus (2002), the $95 \%$ confidence interval of the mean was computed from the pooled error terms of the repeated measures ANOVA. The confidence intervals associated with mean $D L$ and mean $C E$ were \pm 13.9 and $\pm 42.1 \mathrm{msec}$, respectively.

Difference limen. As one would expect according to Weber's law, $D L$ increased with the duration of the standard interval $\left[F(1,19)=207.2, M S_{\mathrm{e}}=1,349.3, p<.001\right]$. The average $D L$ was $24 \mathrm{msec}$ for the short and $108 \mathrm{msec}$ for the long standard. The sensory modality of the first stimulus produced no significant main effect and did not interact with standard duration $\left(F_{\mathrm{s}}<1\right)$. Mean $D L$ was $65 \mathrm{msec}$ when the standard was auditory and $67 \mathrm{msec}$ when it was visual. Nevertheless, the direction and size of this difference agree with PCM, which predicts only a marginally larger $D L$ for auditory than for visual standards. The present results clearly replicated the common finding that temporal discrimination is more precise for auditory than for visual stimuli (see Grondin, 2001). For the short standard, mean $D L$ was $30 \mathrm{msec}$ on $\mathrm{v}-\mathrm{v}$ trials and $13 \mathrm{msec}$ on a-a trials $[t(19)=4.61, p<.001]$. An analogous pattern emerged for the long standard [123 vs. 76 msec; $t(19)=4.87, p<.001]$. Both simple effects were consistent with PCM.
Also in qualitative agreement with PCM, discrimination performance was significantly better in congruent than in incongruent trials $\left[F(1,19)=10.1, M S_{\mathrm{e}}=556.1\right.$, $p=.005]$. Mean DLs were 60 and $72 \mathrm{msec}$, respectively. However, this congruency effect did not vary significantly with the duration of the standard interval $[F(1,19)=2.7$, $\left.M S_{\mathrm{e}}=461.0, p=.116\right]$; a significant congruency effect was obtained for both the short standard [21 vs. $27 \mathrm{msec}$ in the congruent vs. incongruent conditions; $t(19)=2.37$, $p=.028]$ and the long one [ 99 vs. $117 \mathrm{msec}$, respectively; $t(19)=2.63, p=.017]$.

As predicted by PCM, the congruency effect was strongly modulated by the sensory modality of the standard stimulus, as indicated by the significant interaction of congruency and modality $\left[F(1,19)=22.4, M S_{\mathrm{e}}=\right.$ $1,619.5, p<.001]$. As one would expect, performance on temporal discrimination decreased when an auditory standard was combined with a visual rather than with an auditory comparison. In this case, the average $D L$ was $45 \mathrm{msec}$ for congruent and $86 \mathrm{msec}$ for incongruent trials. In line with PCM, temporal discrimination actually improved when a visual standard was combined with an auditory comparison $(D L=58 \mathrm{msec})$ rather than with a visual one $(D L=76 \mathrm{msec})$.

The threefold interaction of all factors revealed that the congruency $\times$ modality interaction became more pronounced as standard duration was increased $[F(1,19)=$ 5.6, $\left.M S_{\mathrm{e}}=1,229.7, p=.029\right]$. For short intervals, $D L$ was $19 \mathrm{msec}$ when the presentation order was $\mathrm{v}-\mathrm{a}$, and it was $36 \mathrm{msec}$ when this order was reversed $[t(19)=2.78$, $p=.012]$. For the long standard, the corresponding figures were 97 and $137 \mathrm{msec}$, respectively $[t(19)=2.24$, $p=.037]$. This threefold interaction is also in accord with PCM.

Constant error. Unlike the $D L$, the $C E$ provides information on whether subjects tend to over- or underestimate the duration of the standard stimulus. Except for the main effect of standard duration $\left[F(1,19)=1.1, M S_{\mathrm{e}}=16,468.7\right.$, $p=.314]$, all factors and their interactions yielded statistically reliable effects on $C E$.

Sensory modality of the standard produced a significant main effect $\left[F(1,19)=11.5, M S_{\mathrm{e}}=10,793.7, p=.003\right]$ : Subjects tended to overestimate the duration of auditory standards in comparison with visual ones ( $C E=25$ vs. $-31 \mathrm{msec}$, respectively). In other words, and consistent with previous research (e.g., Goldstone \& Lhamon, 1974; Wearden et al., 1998), subjects judged auditory standards generally to be longer than visual ones. Also in line with previous research (e.g., Goldstone \& Goldfarb, 1964; Stevens \& Greenbaum, 1966), this modality effect was more pronounced for long than for short standards $[F(1,19)=$ $\left.10.5, M S_{\mathrm{e}}=8,479.6, p=.004\right]$. Furthermore, the main effect of congruency was significant $[F(1,19)=6.4$, $\left.M S_{\mathrm{e}}=5,733.7, p=.020\right]$. $C E$ was different between congruent and incongruent trials (12 vs. $-18 \mathrm{msec}$ ), and this congruency effect was modulated by standard duration $\left[F(1,19)=13.5, M S_{\mathrm{e}}=3,088.6, p=.002\right]$. Both main effects, however, were basically a consequence of the sig- 
nificant interaction of standard modality and congruency $\left[F(1,19)=6.5, M S_{\mathrm{e}}=11,666.8, p=.019\right]$.

Consistent with PCM, $C E$ differed considerably between the two incongruent conditions. Specifically, the average $C E$ was $6 \mathrm{msec}$ on $\mathrm{v}-\mathrm{v}$ trials and $18 \mathrm{msec}$ on a-a trials, whereas it was $-68 \mathrm{msec}$ for $\mathrm{v}-$ a trials and $32 \mathrm{msec}$ for a-v trials. Finally, this twofold interaction was modulated by standard duration $\left[F(1,19)=9.7, M S_{\mathrm{e}}=8,393.5\right.$, $p=.006]$. At variance with PCM, however, the $C E$ difference between both incongruent conditions was only present for long, not for short, standards.

All things considered, $C E$ was most strongly affected when standard and comparison differed in modality and when standard duration was long. Specifically, subjects tended to underestimate the duration of a visual comparison after an auditory standard. By contrast, they were inclined to overestimate the duration of an auditory comparison when it followed a visual standard. This result replicates and extends the findings reported by Goldstone and Goldfarb (1964). Those authors also employed congruent and incongruent trials, on which they asked subjects to judge the duration of a variable comparison on a 9-point rating scale. The duration of the standard was always $1,000 \mathrm{msec}$, and the comparison varied from 600 to $1,400 \mathrm{msec}$. As in the present study, mean judged duration was virtually identical for the two congruent conditions but differed considerably in the incongruent conditions, since auditory stimuli were judged as longer in duration than visual ones. The present results indicate, however, that this intramodal effect on perceived duration depends on stimulus duration (see Wearden et al., 1998, Experiment 3 , for a similar effect).

Summary. The psychophysical data of Experiment 1 agree with the qualitative predictions made by PCM. Most interestingly, the $D L$ data are consistent with the interactions predicted by PCM. In particular, PCM predicted correctly that discrimination performance should be better in $\mathrm{v}-\mathrm{a}$ than in a-v trials. Second, the $C E$ data also tended to be consistent with the predictions of PCM and with previous $C E$ results on crossmodal temporal discrimination. ${ }^{4}$

\section{EXPERIMENT 2}

The data of Experiment 1 support the predictions of PCM and thus validate its assumptions. Nevertheless, it is possible that the outcome of Experiment 1 could be the signature of a different account-for example, if the task requirements forced subjects to adopt a specific strategy. The sensory modalities of both the standard and the comparison varied randomly from trial to trial, so in each trial there was uncertainty about the relevant input modality of both the standard and the comparison. As a result, subjects might have encountered problems in allocating sufficient attentional resources to the relevant input modality. In order to cope with this input uncertainty, the subjects might have ignored to some extent the sensory information of the standard, which occurred before the comparison, but boosted the sensory information of the comparison. Such a strategy would entail a smaller $D L$ with an auditory comparison, because it is well documented that the auditory system has better temporal resolution than the visual system (Goodfellow, 1934), and temporal discrimination performance should then be better for $\mathrm{v}-\mathrm{a}$ than for $\mathrm{a}-\mathrm{v}$ trials. Although PCM also entails this order effect, such an alternative account still needs to be ruled out.

For this reason, Experiment 2 examined the possibility that the previous results reflect strategic effects due to the input uncertainty mentioned above. In order to avoid such input uncertainty, all conditions were blocked in Experiment 2. That is, the sensory modalities of both the standard and the comparison were kept constant across all trials within a separate block. In all other respects, this experiment was identical to Experiment 1.

\section{Method}

Subjects. A fresh sample of 20 subjects was recruited, with 5 male and 15 female adult volunteers ranging in age from 19 to 39 years $(M=24.9, S D=5.5)$. All subjects had normal hearing, normal vision, and were naive about the purpose of the experiment.

Apparatus, Design, and Stimuli. These were identical to those in Experiment 1.

Procedure. The procedure was the same as in Experiment 1, with one modification: The modalities of the standard and the comparison were blocked, so each modality combination ( $\mathrm{a}-\mathrm{a}, \mathrm{v}-\mathrm{v}, \mathrm{a}-\mathrm{v}$, and $\mathrm{v}-\mathrm{a})$ was administered within a single block. As in Experiment 1, there were eight blocks, and the duration of the standard was again changed after the first four blocks. Block order of all modality combinations was controlled across subjects according to a balanced Latin square.

\section{Results and Discussion}

Experiment 2 generally replicated the data of Experiment 1, providing further support for PCM (Figure 4). These new results rule out the possibility that the outcome of Experiment 1 was due to a strategy associated with input uncertainty.

Difference limen. As before, mean $D L$ was smaller for the short than for the long standard duration [16 vs. $\left.101 \mathrm{msec} ; F(1,19)=121.1, M S_{\mathrm{e}}=2,375.8, p<.001\right]$. Also as in Experiment 1, sensory modality of the standard did not produce a significant main effect $[F(1,19)=1.3$, $M S_{\mathrm{e}}=477.4, p=.273$ ] and did not interact with standard duration $\left[F(1,19)=1.4, M S_{\mathrm{e}}=490.1, p=.253\right]$. Yet, in line with PCM, $D L$ was once again somewhat smaller when the standard was auditory rather than visual (56 vs. $60 \mathrm{msec}$ ). $D L$ was also smaller for pure auditory than for pure visual trials [35 vs. $63 \mathrm{msec} ; t(19)=4.69, p<$ $.001]$, and discrimination performance was again better in congruent than in incongruent trials [49 vs. $68 \mathrm{msec}$; $\left.F(1,19)=36.3, M S_{\mathrm{e}}=403.3, p<.001\right]$. The long standard duration even augmented this congruency effect, as revealed by the significant interaction of congruency and standard duration $\left[F(1,19)=21.1, M S_{\mathrm{e}}=446.7, p<\right.$ $.001]$; the size of the congruency effect was $4 \mathrm{msec}$ for the short standard, which increased to $35 \mathrm{msec}$ for the long standard. Congruency once again interacted with the sensory modality of the standard $\left[F(1,19)=25.4, M S_{\mathrm{e}}=\right.$ 961.2, $p<.001]$. As one would expect, discrimination performance was impaired when an auditory standard was combined with a visual comparison $(D L=78 \mathrm{msec})$ in- 


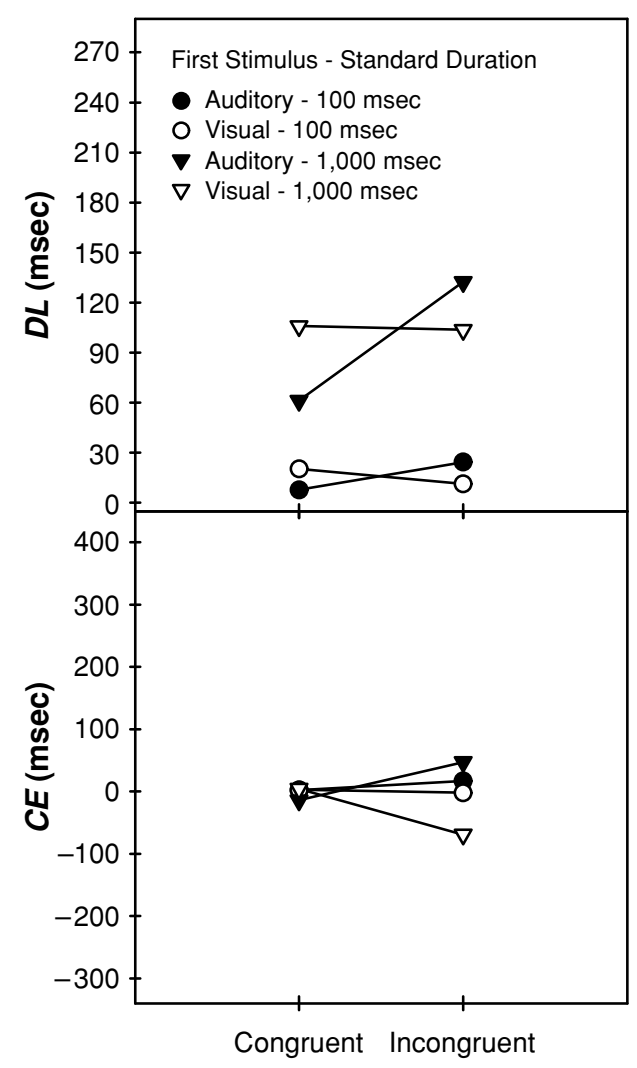

Figure 4. Results of Experiment 2: Mean difference limen (DL, upper panel) and constant error ( $C E$, lower panel) as a function of congruency, modality of the standard, and standard duration. The $95 \%$ confidence intervals associated with mean $D L$ and mean $C E$ were \pm 17.1 and $\pm 52.3 \mathrm{msec}$, respectively.

stead of with an auditory one $(D L=35 \mathrm{msec})[t(19)=$ $8.65, p<.001]$. Discrimination performance appeared to slightly improve, however, when a visual standard was paired with an auditory comparison $(D L=58 \mathrm{msec})$ rather than with a visual one $(D L=63 \mathrm{msec})$, but this difference was not reliable $[t(19)=0.86, p=.402]$. Finally, the threefold interaction of all factors was again significant, since the interaction between congruency and modality turned out to be more pronounced for the long than for the short standard $\left[F(1,19)=7.2, M S_{\mathrm{e}}=797.6\right.$, $p=.015]$.

Constant error. The $C E$ results also agree well with those of Experiment 1, although this time an ANOVA yielded no reliable results. There were no significant main effects nor significant interactions ( $p \mathrm{~s}>.161)$, and only the interaction of modality and congruency approached statistical significance $\left[F(1,19)=3.1, M S_{\mathrm{e}}=19,455.0\right.$, $p=.096]$. As before, $C E$ was virtually identical for the two congruent conditions but appeared to differ for the two incongruent conditions.

Summary. The present results clearly confirm those of Experiment 1. Therefore, the notion that the previous results were due to input uncertainty, and thus to strategies for coping with this uncertainty, has to be rejected.
As before, the complete pattern of results is qualitatively consistent with the predictions of PCM. ${ }^{5}$

\section{EXPERIMENT 3}

The previous two experiments disclosed a striking order effect in which temporal discrimination performance was clearly better on $\mathrm{v}-\mathrm{a}$ than on $\mathrm{a}-\mathrm{v}$ trials. As shown in the introduction, PCM can account for this order effect. Nevertheless, one might be inclined to assume that what matters is merely the order in which the two sensory modalities are processed. According to this simple-order account, discrimination performance should always be better on $\mathrm{v}-\mathrm{a}$ than on $\mathrm{a}-\mathrm{v}$ trials. In order to assess this account, we reversed the presentation order of the comparison and the standard in Experiment 3. PCM makes the rather interesting prediction that this reversal should also reverse discrimination performance on $\mathrm{v}-\mathrm{a}$ and $\mathrm{a}-\mathrm{v}$ trials. ${ }^{6}$ In contrast, the order account predicts that this change should not matter, so that the same effects would be observed as in the previous two experiments.

Figure 5 illustrates the predicted effects of reversing the presentation order of the comparison and the standard. The predictions are based on model parameters identical to those in Figure 2. A comparison of the figures reveals the following similarities and differences: (1) As one would suppose, discrimination performance in congruent trials does not depend on the order of the standard and comparison. (2) Most importantly, discrimination performance in incongruent trials is predicted to reverse, though the average performance in these trials does not depend on the presentation order. In other words, performance should now be better for $\mathrm{a}-\mathrm{v}$ than for $\mathrm{v}-\mathrm{a}$ trials - the predicted reversal effect. Note that this reversal simply reflects the fact that $D L$ is predicted to be smaller when the standard is auditory than when it is visual, because of the higher clock speed associated with auditory than with visual stimuli. As was discussed in our introduction of the PCM, only a small change of $t_{\mathrm{c}}$ is necessary for perceiving a difference between $t_{\mathrm{c}}$ and $t_{\mathrm{s}}$ when the clock speed is relatively high during the processing of the standard. (3) The $C E$ pattern is identical in both figures, except that the new pattern is the old pattern turned upside down. All other effects are predicted to be the same as those in the previous two experiments. $^{7}$

\section{Method}

Subjects. A fresh sample of 20 subjects was recruited, with 3 male and 17 female adult volunteers ranging in age from 19 to 33 years $(M=24.1, S D=4.6)$. All subjects had normal hearing, normal vision, and were naive about the purpose of the experiment.

Apparatus, Design, Stimuli, and Procedure. These were identical to those in Experiment 2. In contrast to Experiment 2, however, the comparison stimulus now preceded the standard stimulus.

\section{Results and Discussion}

Figure 6 depicts the results for mean $D L$ (upper panel) and mean $C E$ (lower panel). A separate ANOVA with the factors standard duration, congruency, and modality of the first stimulus was computed for each dependent measure. 


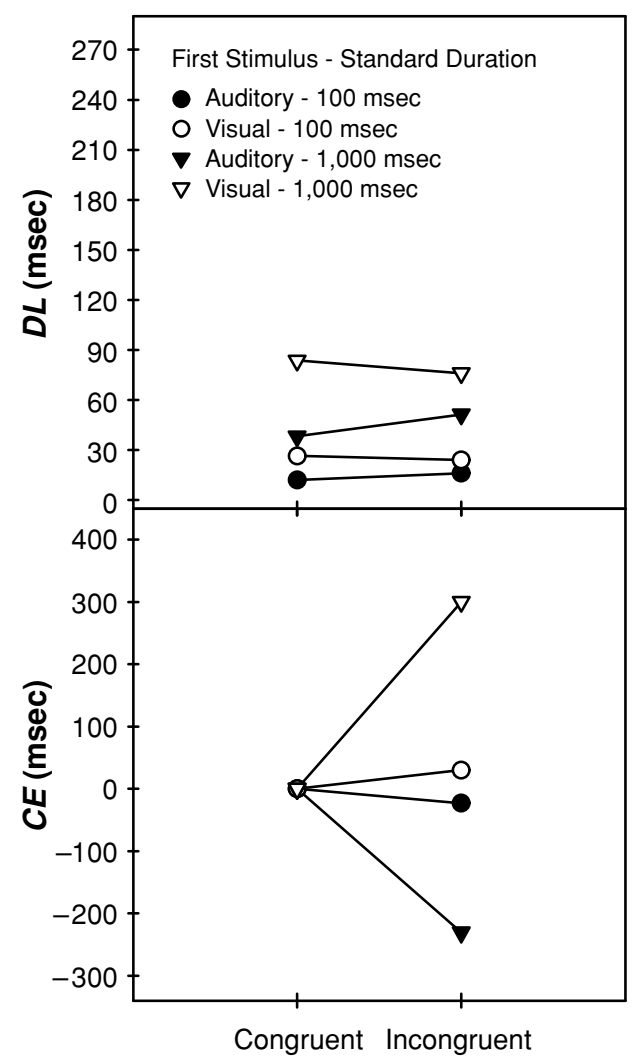

Figure 5. Predicted difference limen ( $D L$, upper panel) and constant error (CE, lower panel) of PCM as a function of congruency, modality of the first stimulus (i.e., the comparison in this case), and standard duration. The legend in the upper panel indicates the modality of the first stimulus and the duration of the standard; for example, "Auditory - 100 msec" means that the first stimulus is auditory and the standard duration is $100 \mathrm{msec}$. The same parameter values were used as in Figure 2.

Difference limen. The pattern of results differed from that of the previous two experiments. Specifically, the results for auditory-first trials were similar, whereas those for visual-first trials were different. Most importantly, temporal discrimination performance was now better for $\mathrm{a}-\mathrm{v}$ than for $\mathrm{v}-\mathrm{a}$ trials, confirming the crucial prediction of PCM. In addition, several other features of the data agree qualitatively with the results of the previous experiment.

It is quite evident that discrimination performance was generally poorer in this experiment than in Experiment 2; the overall mean $D L$ was $58 \mathrm{msec}$ in the previous experiment but $115 \mathrm{msec}$ in this one $[t(24.6)=5.1, p<.001$, two-sided $t$ test with $d f$ corrected for unequal variances]. One reason for the worse overall performance in this experiment was that the response this time was delayed with respect to the relevant comparison stimulus, unlike in the previous two experiments. (We will return to this point in the General Discussion section.)

As in the two previous experiments, $D L$ was considerably larger for the long than for the short standard [40 vs. $191 \mathrm{msec}$ for the short vs. the long standard; $F(1,19)=$ $\left.69.0, M S_{\mathrm{e}}=13,348.5, p<.001\right]$. In contrast to the previ- ous results, temporal sensitivity was higher when the first stimulus was auditory than when it was visual $[F(1,19)=$ $\left.42.1, M S_{\mathrm{e}}=3,990.9, p<.001\right]$. This difference, however, was basically a consequence of the reversed performance effect observed with incongruent trials, which reflected an especially strong deterioration of discrimination performance in $\mathrm{v}-\mathrm{a}$ trials. In addition, this effect was larger for long than for short intervals $\left[F(1,19)=15.1, M S_{\mathrm{e}}=\right.$ $2,523.7, p=.001]$.

Discrimination performance again was clearly better in congruent than in incongruent trials $[D L=93$ vs. $138 \mathrm{msec}$, respectively; $F(1,19)=18.2, M S_{\mathrm{e}}=4,618.8$, $p<.001]$. This effect increased substantially with the duration of the standard interval $\left[F(1,19)=8.4, M S_{\mathrm{e}}=\right.$ $3,556.8, p=.009]$. Because of the reversed performance effect in incongruent trials, the interaction of modality with congruency disappeared this time. In addition, there was no significant interaction of all three factors $(F \mathrm{~s}<1)$.

Constant error. The $C E$ results were analogous to those of Experiments 1 and 2. As one would expect, however, means of the incongruent condition revealed a pattern opposite to the one in the preceding $C E$ results. Although overall mean $C E$ was close to zero, subjects tended to overestimate the comparison when it was short, but to

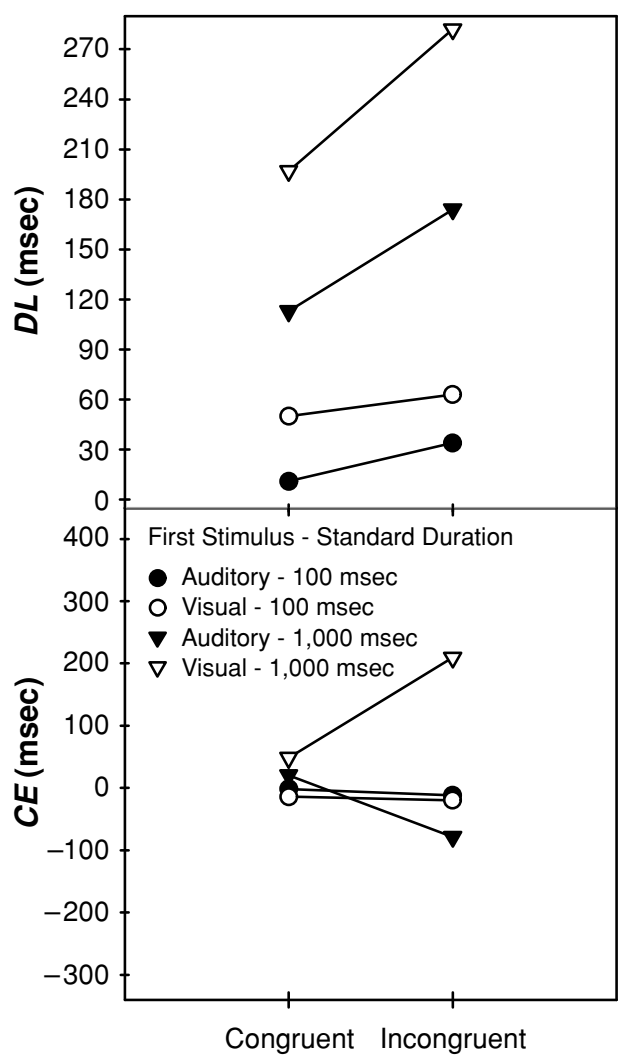

Figure 6. Results of Experiment 3: Mean difference limen ( $D L$, upper panel) and constant error ( $C E$, lower panel) as a function of congruency, modality of the first stimulus, and standard duration. The $95 \%$ confidence intervals associated with mean $D L$ and mean $C E$ were \pm 31.8 and \pm 60.6 msec, respectively. 
underestimate it when it was long $\left[F(1,19)=9.6, M S_{\mathrm{e}}=\right.$ $15,796.3, p=.006]$. As before, subjects tended to underestimate the duration of a visual first stimulus $[F(1,19)=$ $\left.7.9, M S_{\mathrm{e}}=27,802.6, p=.011\right]$, and this tendency was again especially pronounced with the long standard $\left[F(1,19)=14.1, M S_{\mathrm{e}}=20,066.8, p=.001\right]$. Although there was no main effect of congruency $(F<1)$, the interaction of modality and congruency did reach statistical significance $\left[F(1,19)=7.1, M S_{\mathrm{e}}=24,621.1, p=.015\right]$; this interaction effect reflects the fact that $C E$ was close to zero for both congruent conditions but was different from zero, and opposite in sign, for the two incongruent conditions. In contrast to Experiment 1, the interaction of congruency and duration did not reach statistical significance $\left[F(1,19)=1.3, M S_{\mathrm{e}}=12,034.2, p=.275\right]$, which can be attributed to the predicted performance reversal. In line with the preceding results, this interaction was especially pronounced for long standards, as indicated by the threefold interaction of all factors $\left[F(1,19)=8.1, M S_{\mathrm{e}}=\right.$ $20,146.4, p=.010]$.

Summary. In this experiment, the variable comparison was presented before the standard. As implied by PCM, this experimental change reversed discrimination performance for incongruent trials, and this clearly refutes the idea that the performance difference for incongruent trials reflects a mere order effect in which performance is always better for $\mathrm{v}-\mathrm{a}$ than for $\mathrm{a}-\mathrm{v}$ trials. The observed reversal, however, might quite naturally arise from the timing mechanism postulated by PCM, even though this model property is difficult to grasp. ${ }^{8}$ It is also possible that subjects mainly focused on the comparison stimulus. As discussed in the introduction to this experiment, such a strategy could also account for the observed performance reversal. In fact, the overall decrease in temporal discrimination performance relative to the previous experiment provides some evidence for the latter notion.

\section{GENERAL DISCUSSION}

This study assessed whether the generalized pacemakercounter model (Rammsayer \& Ulrich, 2001) provides a reasonable account of the mechanisms underlying crossmodal duration discrimination. In all three experiments, subjects were asked to discriminate between the duration of a constant standard and a variable comparison. The sensory modalities of the standard and the comparison were either congruent $(\mathrm{a}-\mathrm{a}$ or $\mathrm{v}-\mathrm{v})$ or incongruent $(\mathrm{a}-\mathrm{v}$ or $\mathrm{v}-\mathrm{a})$. In $\mathrm{Ex}-$ periments 1 and 2, the standard preceded the comparison, whereas in Experiment 3 the standard followed the comparison. All four experimental conditions were randomized across trials in Experiment 1. In Experiments 2 and 3 , however, each condition was administered in a separate block of trials. The difference limen $D L$ was employed to index temporal discrimination performance, and constant error $C E$ to capture changes in perceived duration.

\section{Main Findings}

These experiments revealed novel results and also confirmed previous findings. First, the $C E$ data confirmed the notion that subjects perceive auditory stimuli to be longer than visual ones of the same duration (e.g., Goldstone \& Goldfarb, 1964; Goldstone \& Lhamon, 1974; Wearden et al., 1998). Second, the $D L$ data replicated established findings of time perception - that is, that discrimination performance diminished as standard duration increased and that performance was worse for visual than for auditory stimuli (see Grondin, 2001). Third, discrimination performance was definitely better in congruent than in incongruent trials, a result that is also in line with those of previous studies (Grondin \& Rousseau, 1991; Grondin, Ivry, Franz, Perreault, \& Metthé, 1996; Klapproth, 2002, 2003). This congruency effect became more pronounced as standard duration increased, and eliminating input uncertainty (Experiment 2) did not remove this effect. Fourth, a strong order effect was obtained on incongruent trials: That is, in Experiments 1 and 2, DL was smaller on $\mathrm{v}-\mathrm{a}$ than on $\mathrm{a}-\mathrm{v}$ trials. In Experiment 3, however, this order effect reversed when the comparison preceded the standard. In other words, discrimination in the incongruent condition was always better with an auditory than with a visual comparison. Finally, reversing the presentation order of the standard and the comparison in Experiment 3 impaired discrimination performance in general.

\section{Pacemaker-Counter Models}

Since the PCM often provides a benchmark in research of time perception (see Grondin, 2001), we further elaborated this model in order to apply it to the crossmodal temporal discrimination task of this study. This elaboration took into account that the rate of pulse generation depends on sensory modality, because previous work has suggested a higher pulse rate for auditory than for visual stimuli (Droit-Volet, 2003; Penney et al., 2000; Wearden et al., 1998). We derived explicit expressions to predict $D L$ and $C E$ from the assumptions of this elaborated model.

As others have found many times in the past (see, e.g., Wing, 2002), this rather simple model captures several aspects of the data. First, the model predicts a higher temporal discrimination performance in the congruent condition with auditory than with visual stimuli. Second, it tends to produce the correct prediction concerning the $C E$. Third, and most surprising to us, it captures the striking order effect in the incongruent condition, correctly accounting for the finding that performance is better in $\mathrm{v}-\mathrm{a}$ trials than in $\mathrm{a}-\mathrm{v}$ trials if the variable comparison follows the standard. Fourth, the model correctly predicts that this order effect should reverse when the comparison occurs before the standard (Experiment 3). Fifth, the model can also account for the finding that some of the observed effects become more pronounced as standard duration increases. For example, according to the model the effect of sensory congruency should increase with standard duration, and we actually observed this pattern, although the observed congruency effect was clearly larger than indicated by PCM.

Nevertheless, this simple model also failed to account for some important aspects of the results. For example, we fitted the model to the data set of each experiment to see whether it would also provide a reasonable quantita- 
tive account. These fits, however, were less impressive, with root mean square errors (RMSEs) ranging from 13 to $35 \mathrm{msec}$. Apart from problems we experienced in identifying the correct model parameters, it is clear that this model is an oversimplification. For example, when we fitted the model, the pulse rate was not allowed to depend on the standard duration, as in the work by Rammsayer and Ulrich (2001), and identical sets of parameters were applied to all subjects. We refrained from increasing the model's complexity, however, because this would have complicated the fitting procedure even more. Given that the model includes relatively few free parameters, it seems possible that future research will be able to advance it.

This quantitative analysis of PCM also clarified that the current version of the model cannot account for the rather large effect of sensory congruency on temporal discrimination performance. This point was revealed by computing the predicted congruency effect from the fits of the model. With the short standard, the observed $D L$ was on average $9.4 \mathrm{msec}$ larger in the incongruent than in the congruent condition. However, PCM predicted an average increase of only $0.6 \mathrm{msec}$. Likewise, the average congruency effect was $41.6 \mathrm{msec}$ with the long standard, yet the predicted effect was only $2.7 \mathrm{msec}$. Thus, it appears possible that temporal discrimination on congruent trials could also benefit from nontemporal sensory information (e.g., experienced arousal) within a single modality, information that is not captured by the present version of PCM. For example, if the experienced level of arousal were the same in single-modality trials, this would inform the subject that the standard and comparison must be physically identical in magnitude and extent. However, the inclusion of such additional sensory cues would no longer be beneficial when both stimuli belonged to different sensory modalities. In agreement with this proposal, Rammsayer and Ulrich (2005) found a performance decrement in temporal discrimination when loudness (i.e., arousal) differed between an auditory standard and an auditory comparison interval versus when they were equally loud. Although a complete assessment of this proposal is beyond the scope of the present study, future work should address in greater detail why discrimination performance is usually better when both stimuli belong to the same sensory modality, and extend PCM accordingly.

Finally, there was another finding that cannot be explained within the present framework of PCM without invoking further assumptions. As mentioned above, average $D L$ was larger in Experiment 3 than in Experiments 1 and 2. That is, discrimination performance was better when the standard came before rather than after the variable comparison. This outcome, however, can be easily addressed within the framework of the entrainment model (Large \& Jones, 1999). The sequence of time intervals within a single trial in Experiments 1 and 2 formed an isochronous induction sequence (Barnes \& Jones, 2000) before the comparison was presented. For example, in the long-standard condition the temporal sequence of a trial was as follows: $1,000 \mathrm{msec}$ (warning signal offset to standard onset) $-1,000 \mathrm{msec}$ (standard duration)-1,000 msec (standard offset to comparison onset). In other words, the induction sequence was composed of three 1,000-msec intervals before the variable comparison was delivered. This induction sequence might have entrained an activity, an internal rhythm that facilitated the processing of the comparison at the end of this sequence (see Barnes \& Jones, 2000; McAuley \& Jones, 2003). In Experiment 3, however, the induction sequence before the comparison was reduced to only one induction interval, and thus there was less opportunity to build up such an entraining activity. Consequently, discrimination performance in Experiment 3 was less promoted by this activity than had been the case in Experiments 1 and 2. Thus, another option to advance PCM further would be to link its core assumptions to the assumptions of the entrainment model.

\section{One Timing Mechanism or Several?}

A fundamental assumption of PCM is that a single timing mechanism underlies the perception of time. This notion, however, was already challenged by Hugo Münsterberg (1889). He reasoned that the mechanism underlying the perception of short durations is qualitatively different from the one that underlies the perception of long durations. More specifically, Münsterberg assumed that durations less than one third of a second can be directly perceived, since they are primarily processed by sensory mechanisms. By contrast, longer durations, he believed, cannot be immediately perceived but need to be reconstructed by higher mental processes. Similarly, Michon (1985) argued that temporal processing of intervals longer than approximately half a second is cognitively mediated, whereas temporal processing of shorter intervals is supposedly "of a highly perceptual nature, fast, parallel and not accessible to cognitive control" (Michon, 1985, p. 40). Several authors have endorsed this view of distinct timing mechanisms (e.g., Buonomano \& Karmarkar, 2002; Frankenhaeuser, 1959; Lewis \& Miall, 2003; Mitrani, Shekerdjiiski, Gourevitch, \& Yanev, 1977; Rammsayer, 1999; Sturt, 1925). ${ }^{9}$

Although experimental work pertinent to this issue is still extremely scant, it has recently received a fresh impetus in the field of timing and time perception (e.g., Michon, 1985; Rammsayer, 1999; Rammsayer \& Lima, 1991; Rammsayer \& Ulrich, 2005) and in the cognitive neurosciences (Bendixen et al., 2005; Grimm, Widmann, \& Schröger, 2004; Lewis \& Miall, 2003). For example, Lewis and Miall recently reviewed neuroimaging data on various temporal tasks. Their review included studies on timing tasks such as temporal production, tapping, response synchronization, velocity discrimination, and temporal discrimination. They concluded that an automatic timing system is involved in the timing of intervals in the range below $1 \mathrm{sec}$. This system is assumed to recruit primarily networks within premotor and motor brain areas and is not amenable to attention. The other hypothesized timing system is subject to cognitive control associated with activities in prefrontal and parietal brain regions.

The results of the present experiments, however, do not support the idea that distinct timing mechanisms operate at short and long durations. In all three experiments, 
a similar and robust pattern of results emerged for short and long durations. For example, temporal discrimination performance was identically affected by our experimental manipulations at both short and long durations. This consistent pattern clearly supports the single-clock assumption of PCM and puts in question the idea of two distinct timing mechanisms. An identical conclusion was recently reached by Rammsayer and Ulrich (2005) on the basis of psychophysical data from a dual-task approach. Thus, the present results and those of Rammsayer and Ulrich (2005) appear rather surprising if one considers the evidence from neuroimaging (Lewis \& Miall, 2003) and neuropharmacological (Rammsayer, 2003) studies that put forward the notion of two distinct timing mechanisms. In order to reconcile the psychophysical data with the conclusion stemming from these cognitive neuroscience approaches, one might propose that different versions of the same internal clock are located in various brain regions. ${ }^{10}$

\section{Conclusion}

In summary, we applied the PCM to crossmodal temporal discrimination. This model provides a reasonable qualitative account for explaining some intriguing aspects of the data, such as that temporal discrimination depends on the presentation order of sensory modalities. The present data are also consistent with the fundamental notion of PCM, which claims that one and the same single-clock mechanism is involved in the time perception of short and longer durations. Nevertheless, the model in its present formulation can account neither for the relatively large observed congruency effect nor for the finding that the presentation order of the standard and the comparison stimulus has a strong effect on temporal discrimination. We have provided some suggestions in order to accommodate these findings within the framework of current psychophysical models of time perception.

\section{REFERENCES}

Allan, L. G., \& Kristofferson, A. B. (1974). Psychophysical theories of duration discrimination. Perception \& Psychophysics, 16, 26-34.

Barnes, R., \& Jones, M. R. (2000). Expectancy, attention, and time. Cognitive Psychology, 41, 254-311.

Bendixen, A., Grimm, S., \& Schröger, E. (2005). Human auditory event-related potentials predict duration judgments. Neuroscience Letters, 383, 284-288.

BorInG, E. G. (1957). A history of experimental psychology (2nd ed.). New York: Appleton-Century-Crofts.

Buonomano, D. V., \& Karmarkar, U. R. (2002). How do we tell time? Neuroscientist, $\mathbf{8}, 42-51$.

Creelman, C. D. (1962). Human discrimination of auditory duration. Journal of the Acoustical Society of America, 34, 582-593.

Droit-VoleT, S. (2003). Temporal experience and timing in children. In W. H. Meck (Ed.), Functional and neural mechanisms of interval timing (pp. 183-208). Boca Raton, FL: CRC Press.

Fetterman, J. G., \& Killeen, P. (1995). Categorical scaling of time: Implications for clock-counter models. Journal of Experimental Psychology: Animal Behavior Processes, 21, 43-63.

Frankenhaeuser, M. (1959). Estimation of time, an experimental study. Stockholm: Almqvist \& Wiksell.

GibBon, J. (1977). Scalar expectancy theory and Weber's law in animal timing. Psychological Review, 84, 279-325.

GibBon, J. (1991). Origins of scalar timing theory. Learning \& Motivation, 22, 3-38.
Goldstone, S., \& GoldFarb, J. L. (1964). Auditory and visual time judgment. Journal of General Psychology, 70, 369-387.

Goldstone, S., \& Lhamon, W. T. (1974). Studies of auditory-visual differences in human time judgment: 1 . Sounds are judged longer than lights. Perceptual \& Motor Skills, 39, 63-82.

Goodfellow, L. D. (1934). An empirical comparison of audition, vision, and touch in the discrimination of short intervals of time. American Journal of Psychology, 46, 243-258.

Grimm, S., Widmann, A., \& Schröger, E. (2004). Differential processing of duration changes within short and long sounds in humans. Neuroscience Letters, 356, 83-86.

Grondin, S. (2001). From physical time to the first and second moments of psychological time. Psychological Bulletin, 127, 22-44.

Grondin, S. (2003). Studying psychological time with Weber's law. In R. Buccheri, M. Saniga, \& W. M. Stuckey (Eds.), The nature of time: Geometry, physics, and perception (pp. 33-41). Dordrecht: Kluwer.

Grondin, S., Ivry, R. B., Franz, E., Perreault, L., \& Metthé, L. (1996). Markers' influence on the duration discrimination of intermodal intervals. Perception \& Psychophysics, 58, 424-433.

Grondin, S., Meilleur-Wells, G., \& Lachance, R. (1999). When to start explicit counting in a time-intervals discrimination task: A critical point in the timing process of humans. Journal of Experimental Psychology: Human Perception \& Performance, 25, 993-1004.

Grondin, S., \& Rousseau, R. (1991). Judging the relative duration of multimodal short empty time intervals. Perception \& Psychophysics, 49, 245-256.

Ivry, R. B., \& Hazeltine, R. E. (1995). Perception and production of temporal intervals across a range of durations: Evidence for a common timing mechanism. Journal of Experimental Psychology: Human Perception \& Performance, 21, 3-18.

KaERnBaCH, C. (1991). Simple adaptive testing with the weighted updown method. Perception \& Psychophysics, 49, 227-229.

KANT, I. (1998). Kritik der reinen Vernunft [Critique of pure reason]. Hamburg: Meiner. (Original work published 1787)

KilleEn, P. R., \& TAYloR, T. J. (2000). How the propagation of error through stochastic counters affects time discrimination and other psychophysical judgments. Psychological Review, 107, 430-459.

Klapproth, F. (2002). The effect of study-test modalities on the remembrance of subjective duration from long-term memory. Behavioural Processes, 59, 37-46.

KLAPproth, F. (2003). Notable results regarding temporal memory and modality. In H. Helfrich (Ed.), Time and mind II: Information processing perspectives (pp. 79-96). Göttingen: Hogrefe \& Huber.

LARGE, E. W., \& Jones, M. R. (1999). The dynamics of attending: How we track time varying events. Psychological Review, 106, 119-159.

LEWIS, P. A., \& MiALl, R. C. (2003). Distinct systems for automatic and cognitively controlled time measurement: Evidence from neuroimaging. Current Opinion in Neurobiology, 13, 250-255.

LofTUs, G. R. (2002). Analysis, interpretation, and visual presentation of experimental data. In H. Pashler (Ed.), Stevens 'handbook of experimental psychology: Vol. 4. Methodology in experimental psychology (3rd ed., pp. 339-390). New York: Wiley.

MACH, E. (1865). Untersuchungen über den Zeitsinn des Ohres. Sitzungsberichte der mathematisch-naturwissenschaftlichen Classe der Kaiserlichen Akademie der Wissenschaften, 51, 133-150.

Mattes, S., \& UlRICH, R. (1998). Directed attention prolongs the perceived duration of a brief stimulus. Perception \& Psychophysics, 60, 1305-1317.

McAuley, J. D., \& Jones, M. R. (2003). Modeling effects of rhythmic context on perceived duration: A comparison of interval and entrainment approaches to short-interval timing. Journal of Experimental Psychology: Human Perception \& Performance, 29, 1102-1125.

MEck, W. H. (ED.) (2003). Functional and neural mechanisms of interval timing. Boca Raton, FL: CRC Press.

Michon, J. A. (1985). The compleat time experiencer. In J. A. Michon \& J. L. Jackson (Eds.), Time, mind, and behavior (pp. 21-52). Berlin: Springer.

Mitrani, L., Shekerdjisski, S., Gourevitch, A., \& Yanev, S. (1977). Identification of short time intervals under $\mathrm{LSD}_{25}$ and mescaline. $A c$ tivitas Nervosa Superior, 19, 103-104.

Münsterberg, H. (1889). Beiträge zur experimentellen Psychologie: Heft 2. Freiburg: Mohr. 
Nobre, A. C., \& O'Reilly, J. (2004). Time is of the essence. Trends in Cognitive Sciences, 8, 387-389.

Penney, T. B., Gibbon, J., \& Meck, W. H. (2000). Differential effects of auditory and visual signals on clock speed and temporal memory. Journal of Experimental Psychology: Human Perception \& Performance, 26, 1770-1787.

POYNTER, D. (1989). Judging the duration of time intervals: A process of remembering segments of experience. In I. Levin \& D. Zakay (Eds.), Time and human cognition: A life-span perspective (pp. 305-331). Amsterdam: North-Holland.

RAMMSAYER, T. H. (1999). Neuropharmacological evidence for different timing mechanisms in humans. Quarterly Journal of Experimental Psychology, 52B, 273-286.

RAMMSAYER, T. H. (2003). Sensory and cognitive mechanisms in temporal processing elucidated by a model systems approach. In H. Helfrich (Ed.), Time and mind II: Information processing perspectives (pp. 97 113). Göttingen: Hogrefe \& Huber.

Rammsayer, T. H., \& Grondin, S. (2000). Psychophysics of human timing. In R. Miller (Ed.), Time and the brain (pp. 157-167). Reading, U.K.: Harwood

Rammsayer, T. H., \& Lima, S. D. (1991). Duration discrimination of filled and empty auditory intervals: Cognitive and perceptual factors. Perception \& Psychophysics, 50, 565-574.

Rammsayer, T. [H.], \& UlRich, R. (2001). Counting models of temporal discrimination. Psychonomic Bulletin \& Review, 8, 270-277.

RAMmSAYER, T. [H.], \& UlRICH, R. (2005). No evidence for qualitative differences in the processing of short and long temporal intervals. Acta Psychologica, 120, 141-171.

ROECKELEIN, J. E. (2000). The concept of time in psychology: A resource book and annotated bibliography. Westport, CT: Greenwood Press.

Stevens, S. S., \& Greenbaum, H. B. (1966). Regression effect in psychophysical judgment. Perception \& Psychophysics, 1, 439-446.

Sturt, M. (1925). The psychology of time. London: Kegan Paul.

Treisman, M., Faulkner, A., Naish, P. L. N., \& Brogan, D. (1990). The internal clock: Evidence for a temporal oscillator underlying time perception with some estimates of its characteristic frequency. Perception, 19, 705-743.

VIERORDT, K. (1868). Der Zeitsinn nach Versuchen. Tübingen: Laupp.

Wearden, J. H., Edwards, H., Fakhri, M., \& Percival, A. (1998). Why "sounds are judged longer than lights": Application of a model of the internal clock in humans. Quarterly Journal of Experimental Psychology, 51B, 97-120.

WING, A. M. (2002). Voluntary timing and brain function: An information processing approach. Brain \& Cognition, 48, 7-30.

\section{NOTES}

1. As demonstrated by Rammsayer and Ulrich (2001), this approximation is usually excellent.

2. It should be noted, however, that this explanation is somewhat oversimplified, because it completely discounts the variance of the interpulse time

3. Alternatively, a positive (or negative) $C E$ may also be interpreted as indicating that subjects underestimate (or overestimate) the duration of the comparison.
4. In order to evaluate whether PCM also provides a reasonable quantitative account of the present data, a simplex search algorithm was used to minimize the root mean square error $(R M S E)$ between observed and predicted values. The minimizing procedure operated simultaneously on the $C E$ and $D L$ data sets. Predicted values for $C E$ and $D L$ were calculated via Equations 6 and 8, respectively. The overall error of this fit was $R M S E=20.9 \mathrm{msec}$, which suggests that $\mathrm{PCM}$ does not provide a satisfactory quantitative account. There are, however, at least two reasons why the fits might be suboptimal, even if PCM was approximately correct. First, such search algorithms do not always find the optimal parameter estimates (e.g., because of problems with local minima). Hence, PCM might actually produce somewhat better fits than the error suggests. In fact, the parameter estimates were rather sensitive to the starting values of the minimizing routine, but the RMSE was not, indicating that the true parameter values were not identifiable (see also Rammsayer \& Ulrich, 2001). Second, PCM was fitted to aggregated results, so the assessment implicitly required an identical set of parameter values to be applied to each subject. This requirement, however, might be too strict, and thus unrealistic.

5. The model predictions were again fitted simultaneously to the $D L$ and $C E$ results. Although the overall RMSE of $13.1 \mathrm{msec}$ was somewhat better than that for the previous experiment, it still does not indicate a perfect quantitative fit.

6. It is easy to see that Equations 6 and 8 would also apply to this case.

7. Although it is not shown in Figure 5, the model can also make a prediction that is slightly different qualitatively, but this prediction is not of particular relevance for the purpose of this study. According to this alternative, the $D L$ difference between conditions $\mathrm{v}-\mathrm{v}$ and a-a is smaller than the difference between conditions $\mathrm{v}-\mathrm{a}$ and $\mathrm{a}-\mathrm{v}$. The choice of parameters determines whether this somewhat different pattern would emerge. It should be noted, however, that this alternative pattern would also entail the crucial features (1), (2), and (3) that we mentioned above.

8. The overall fit of the pacemaker-counter model was $R M S E=$ $34.9 \mathrm{msec}$ in this experiment, and thus was notably worse than the fit in the two previous experiments.

9. Another topic in the timing literature relates to the issue of whether different timing mechanisms underlie the perception and production of temporal intervals. Experimental and neuropsychological research suggests that a common mechanism is involved in both tasks (e.g., Ivry \& Hazeltine, 1995).

10. In an experiment with 28 subjects, we employed stimulus durations of 50 and 2,000 msec to examine whether the findings of Experiment 1 generalize to a larger range of stimulus durations. Temporal discrimination became very difficult for our subjects at the long standard durations, and thus the obtained $D L s$ were extremely large and unreliable. Power analysis revealed that a huge sample size would be needed to attain the same level of statistical power as in Experiment 1. Nevertheless, the pattern of results was very similar to the one in Experiment 1, and a strong congruency effect once again emerged for both short and long durations. This indicates that our conclusions may generalize to a larger range of stimulus durations.

(Manuscript received May 23, 2005; revision accepted for publication November 4, 2005.) 